\title{
THE EFFECT OF EPINEPHRIN IN CIRCULATORY COLLAPSE INDUCED BY SODIUM NITRITE
}

\author{
BY ROBERT W. WILKINS, SOMA WEISS AND FLORENCE W. HAYNES \\ (From the Thorndike Memorial Laboratory, Second and Fourth Medical Services (Harvard), \\ Boston City Hospital, and the Department of Medicine, Harvard Medical \\ School, Boston)
}

(Received for publication September 7, 1937)

Previous studies $(1,2)$ of vasomotor collapse induced by sodium nitrite in normal subjects in the upright position have revealed that the characteristic symptoms and signs of collapse are manifested by a fall in the arterial pressure, particularly the pulse pressure, as well as in the venous pressure. Further, the collapse is accompanied by an increase in arterial and arteriolar tone, but a decrease in venous tone. The blood flow through the hand is unchanged during the early stage of collapse as a result of compensatory vascular changes; later, however, there is a sharp fall in the blood flow which is followed by syncope. The manifestations and mechanism of this collapse are identical with those seen in disease. Since epinephrin is one of the agents commonly used in the treatment of collapse, it was decided to investigate the mode of action and the therapeutic efficacy of this drug in experimental nitrite collapse. Such a controlled study is of interest, because similar observations are not feasible in collapse occurring in patients who are gravely ill.

\section{METHOD}

The subjects rested in a comfortable horizontal position for at least 30 minutes after all apparatus had been adjusted and before any observations were begun. The heart rate was counted by arterial palpation, by precordial auscultation or from the plethysmographic tracings. Arterial pressure was determined in the upper arm at heart level by the auscultatory method, using a mercury manometer. Venous pressures in the foot were taken in the horizontal position by the indirect method of Krogh, Turner and Landis (3).

We have found some difficulty in obtaining consistent results with the indirect method for the determination of venous pressure in the foot with the subject in the upright position. This was due mainly to the general engorgement and suffusion of the skin of the feet. Smirk (4) has recently measured the venous pressure in the foot by the direct method in both the horizontal and the upright position. He has shown that slight motion of the leg followed by relaxation, such as shifting the weight from one leg to another, causes a fall in the pres- sure. The intervention of valves in the leg veins plays an important rôle in these changes of pressure. There are no valves between the femoral veins and the heart so that femoral venous pressure remains at least at the pressure in the right auricle. Simultaneous direct measurements of pressure in the femoral and foot veins have not been done but might be of significance.

In a few experiments venous pressures were determined in the horizontal and also in the upright position at the femoral vein by the direct method of Moritz and von Tabora (5). All measurements are given in relation to the right auricle at the second intercostal space.

The blood flow was measured in the hands by Freeman's modification (6) of the plethysmographic method of Hewlett and Van Zwaluwenburg (7), and venous tone in the hands by a modification (2) of the plethysmographic method of Capps (8). A single measurement, the increase in hand volume caused by raising the venous pressure from 10 to $30 \mathrm{~mm}$. $\mathrm{Hg}$, was used to indicate venous tone, calculated as cc. per liter of hand. The right hand was maintained at $32^{\circ} \mathrm{C}$., or normal skin temperature. The left hand was fully dilated by a local temperature of $45^{\circ} \mathrm{C}$. in most experiments, but in a few the left hand was maintained at $37.5^{\circ} \mathrm{C}$., body temperature, to avoid the possible objection that one hand was at an unphysiological temperature. The venous tone was not computed in the hand at $45^{\circ} \mathrm{C}$. since it has been found that in some subjects the test is invalid at temperatures above $40^{\circ} \mathrm{C}$. (2).

The experiments consisted in the following procedures carried out on the same subject. After repeated control measurements had been obtained, observations were made on different days on the effects of: (1) elevation to an upright position (75 degrees) for 30 minutes, followed by return to horizontal position; (2) oral administration of from 0.12 to 0.18 gram ( 2 to 3 grains) of sodium nitrite in the horizontal position, followed in 15 to 25 minutes by elevation to the upright position; (3) subcutaneous administration of from 0.5 to $1.0 \mathrm{mgm}$. ( 0.5 to $1.0 \mathrm{ml}$. of a $1: 1000$ solution) of epinephrin, followed in 5 to 15 minutes by elevation to the upright position for 30 minutes and return to horizontal ; (4) administration of the same dose of sodium nitrite and, in 5 to 15 minutes, the same dose of epinephrin, followed in 5 to 15 minutes by elevation to the upright position.

While in the upright position the subject was urged to remain motionless. At the height of the collapse, which was associated with syncope, the subject was promptly returned to the horizontal position and observa- 
tions continued for 30 minutes. Observations were also made in the horizontal position only, in order to determine more accurately the circulatory effects of the same doses of epinephrin or nitrite alone.

Nine young normal adults served as subjects. Four of them had a complete series of experiments, as outlined above. Another had the same except that direct femoral venous pressures were done and the plethysmographic studies were omitted. The other subjects were studied only in the horizontal position in order to determine the effects of epinephrin, alone or following sodium nitrite, on the several aspects of the circulation investigated.

\section{RESULTS}

There was a general uniformity of symptoms, signs and circulatory measurements in all the subjects under the same experimental conditions. Figures 1 through 4 show the results of a complete series of tilting experiments on a normal male subject, J. A., aged 26.

Figure 1 demonstrates the normal adaptation to the upright position, characterized by a gradual increase in heart rate, lowering of systolic and

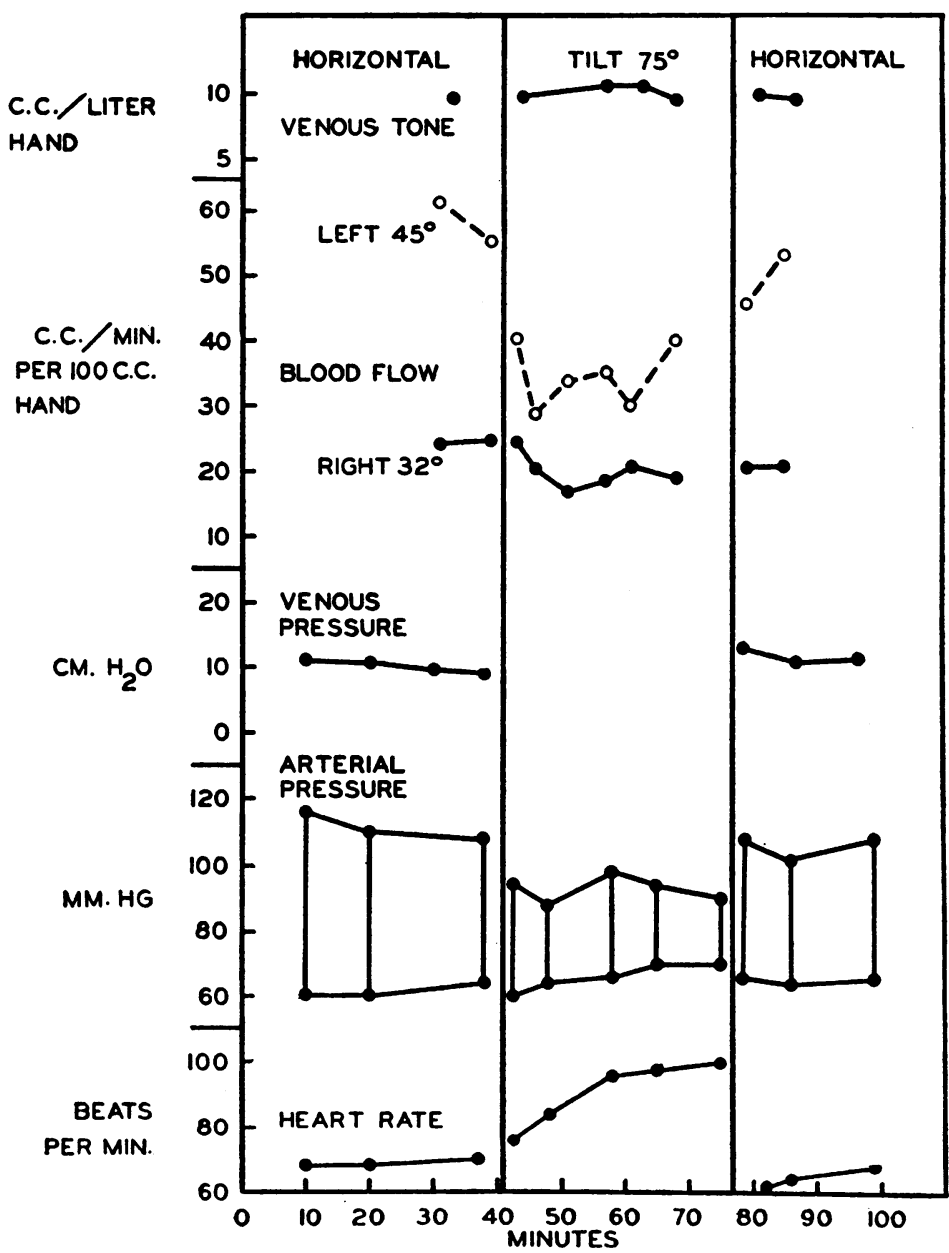

Fig. 1. Subject J. A. Effect of Tilting to 75 Degrees

From the top to the bottom the curves of circulatory measurements are as follows: venous tone as measured by the increase in hand volume caused by raising the venous pressure from 10 to $30 \mathrm{~mm}$. $\mathrm{Hg}$ (note that an increase in venous tone is denoted by a decrease in the plotted value), blood flow in the left hand at a warm temperature and in the right hand at a cooler temperature, venous pressure in the foot in the horizontal position, the systolic and diastolic arterial blood pressure and the heart rate. 


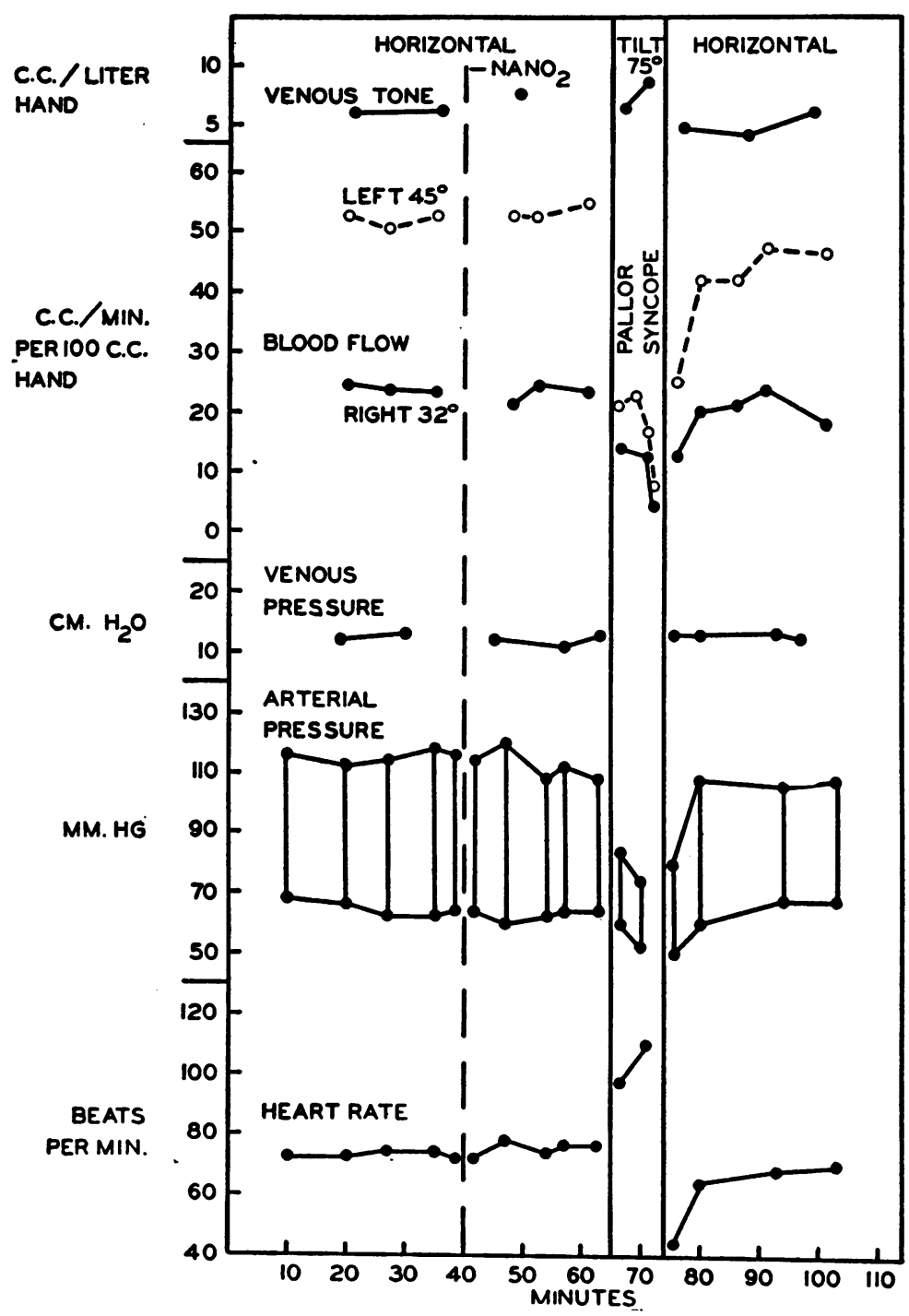

Fig. 2. Subject J. A. Effect of the Administration of 0.18 gram of Sodium Nitrite, Followed by Tilting to 75 Degrees

Curves as in Figure 1.

elevation of diastolic arterial pressure, and moderate decrease in blood flow in the normal hand at $32^{\circ} \mathrm{C}$., but a proportionately greater decrease in flow in the dilated hand at $45^{\circ} \mathrm{C}$. There was no significant change in venous tone in the hand. There were no symptoms during 35 minutes of motionless standing. On return to the horizontal position these various circulatory measurements resumed the control levels.

Figure 2 shows a typical experiment with rapid collapse in the upright position after 0.18 gram ( 3 grains) of sodium nitrite. While still in the horizontal position the only significant change in the circulation after the administration of nitrite was a slight decrease in venous tone, as indicated by a greater volume change in the hand with a standard venous pressure. Further proof of the generalized loss of venous tone was the quick onset of collapse on elevation to the upright position (2). The heart rate rose and the arterial pressure, particularly the systolic, fell. Arterial blood flow decreased very markedly in both the dilated and the normal hand. Venous tone continued to decrease. Along with these circulatory 
changes there were signs and symptoms of collapse, namely, marked pallor, sweating, weakness, nausea and air hunger, finally culminating in syncope after 9 minutes. On return to the horizontal position these changes reverted to normal.

Figure 3 shows the effect of the subcutaneous administration of $1 \mathrm{mgm}$. of epinephin, followed in 15 minutes by elevation to the upright position. After epinephrin there was an increase in pulse rate, an elevation of systolic arterial pressure and a lesser decrease in diastolic pressure. There was a marked decrease in blood flow in both the normal hand at $32^{\circ}$ and the dilated hand at $45^{\circ} \mathrm{C}$. Venous tone increased, as indicated by decreased distention of the venous vessels of the hand. The subject experienced a feeling of excitement, with slight tremors. On elevation to the upright position the heart rate became further increased, and there was a slight decrease in diastolic and increase in systolic arterial pressure. With continued standing the blood flow and venous tone in the hand slowly returned toward normal. The only signs and symptoms were pallor of the face, slight sweating and tremor. This man, like most

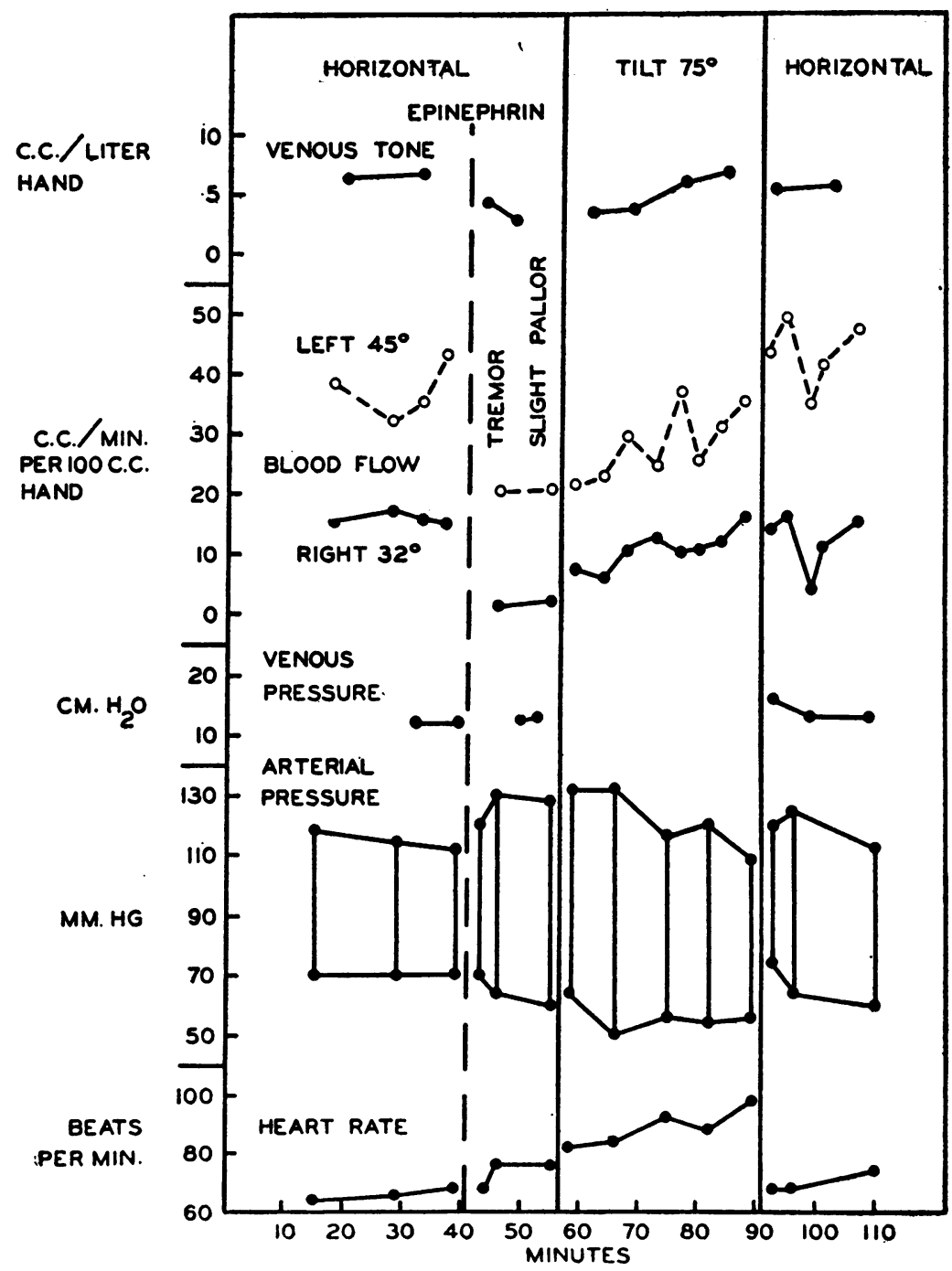

Fig. 3. Subject J. A. Effect of the Administration of 1.0 mgm. of EpiNePhrin, Followed by Tilting to 75 Degrees

Curves as in Figure 1. 


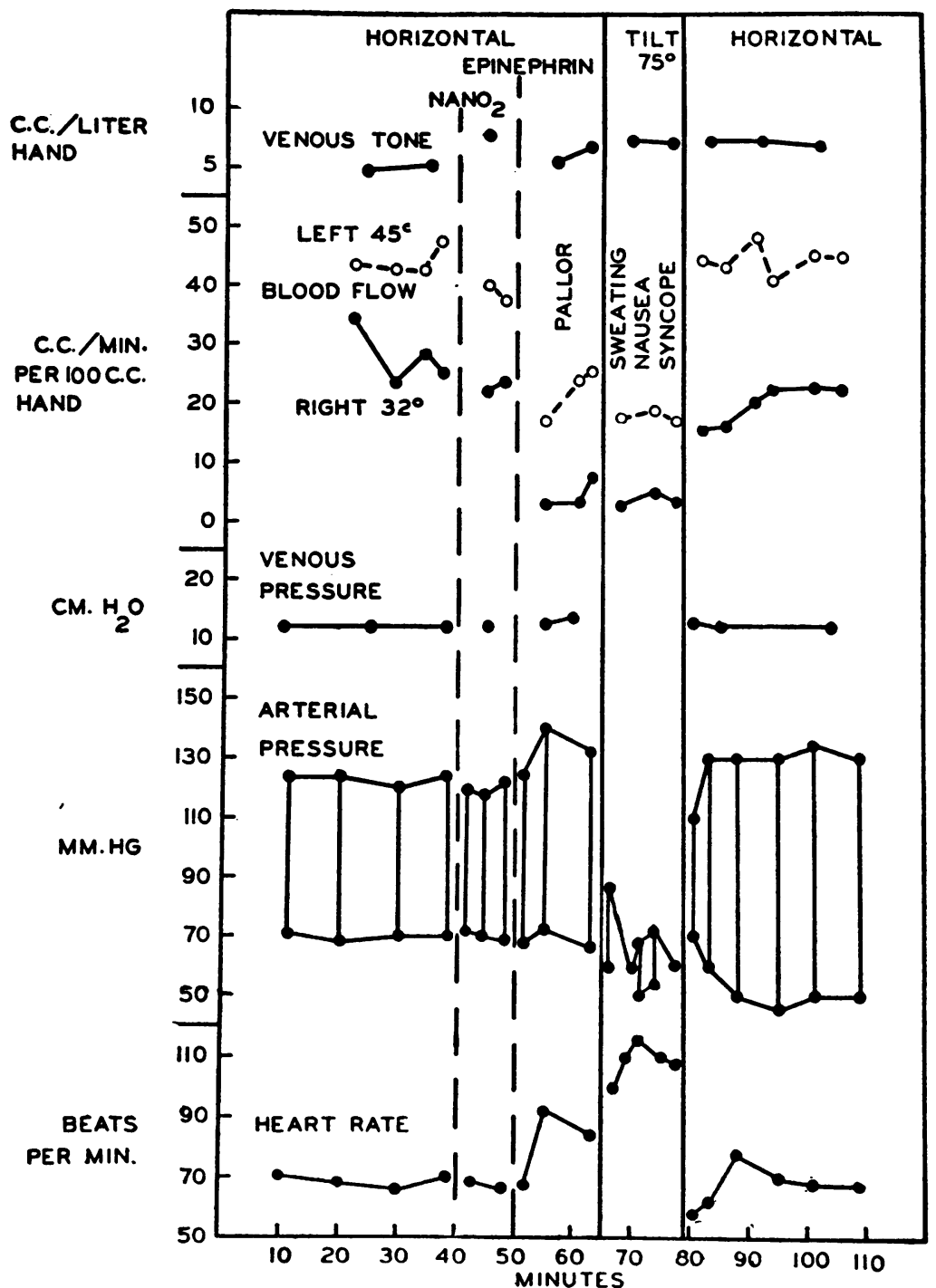

Fig. 4. Subject J. A. Effect of the Administration of 0.18 gram of Sodium Nitrite AND 1.0 mgm. of Epinephrin, Followed by Tilting to 75 DEGREES

Curves as in Figure 1.

of the subjects, found the standing after epinephrin more uncomfortable than normal standing.

Figure 4 shows the effect of the same dose of sodium nitrite and, in 10 minutes, the same dose of epinephrin, followed 15 minutes later by tilting to the upright position. Except for a decrease in venous tone there were no significant changes after the nitrite. After the epinephrin there was an increase in heart rate and in systolic arterial pressure and no change in diastolic pres- sure. The venous pressure in the foot increased slightly. The blood flow in both hands decreased very markedly. Venous tone in the hand first increased, then decreased again.

On elevation to the upright position there was an immediate collapse with subjective weakness. The heart rate increased; systolic arterial pressure fell markedly and at times could not be obtained. Blood flow remained low. Venous tone in the hand remained unaltered, as did the cyanosis over the dependent part of the body. 
The circulatory changes were accompanied by marked pallor of the face, sweating, nausea, air hunger and finally syncope. On return to the horizontal position the various circulatory measurements rapidly returned to the levels at which they had been before the tilting.

This subject was the only one who was able to stand for a longer period after nitrite and epinephrin than after nitrite alone. Signs of collapse, however, occurred earlier and were more pronounced after both drugs than after nitrite alone, for the subject showed manifestations of collapse immediately after tilting and almost fainted within 5 minutes, although he rallied again before syncope actually occurred.
All the other subjects were less able to stand and experienced symptoms of circulatory collapse earlier after both epinephin and nitrite than after nitrite alone. This is shown clearly by comparing the figures on Subject S. S., a robust male, 29 years of age, who was able to stand for 25 minutes after 0.18 gram ( 3 grains) of sodium nitrite (Figure 5), but who developed collapse soon after tilting and fainted after only 8 minutes' standing (Figure 6) after the same dose of nitrite followed by $1.0 \mathrm{mgm}$. of epinephrin. The syncope after both drugs and tilting was preceded by the typical signs and symptoms of collapse, namely, palpitation, pallor, tremor, weakness, sweating, nausea, air hunger and ashen cyanosis.

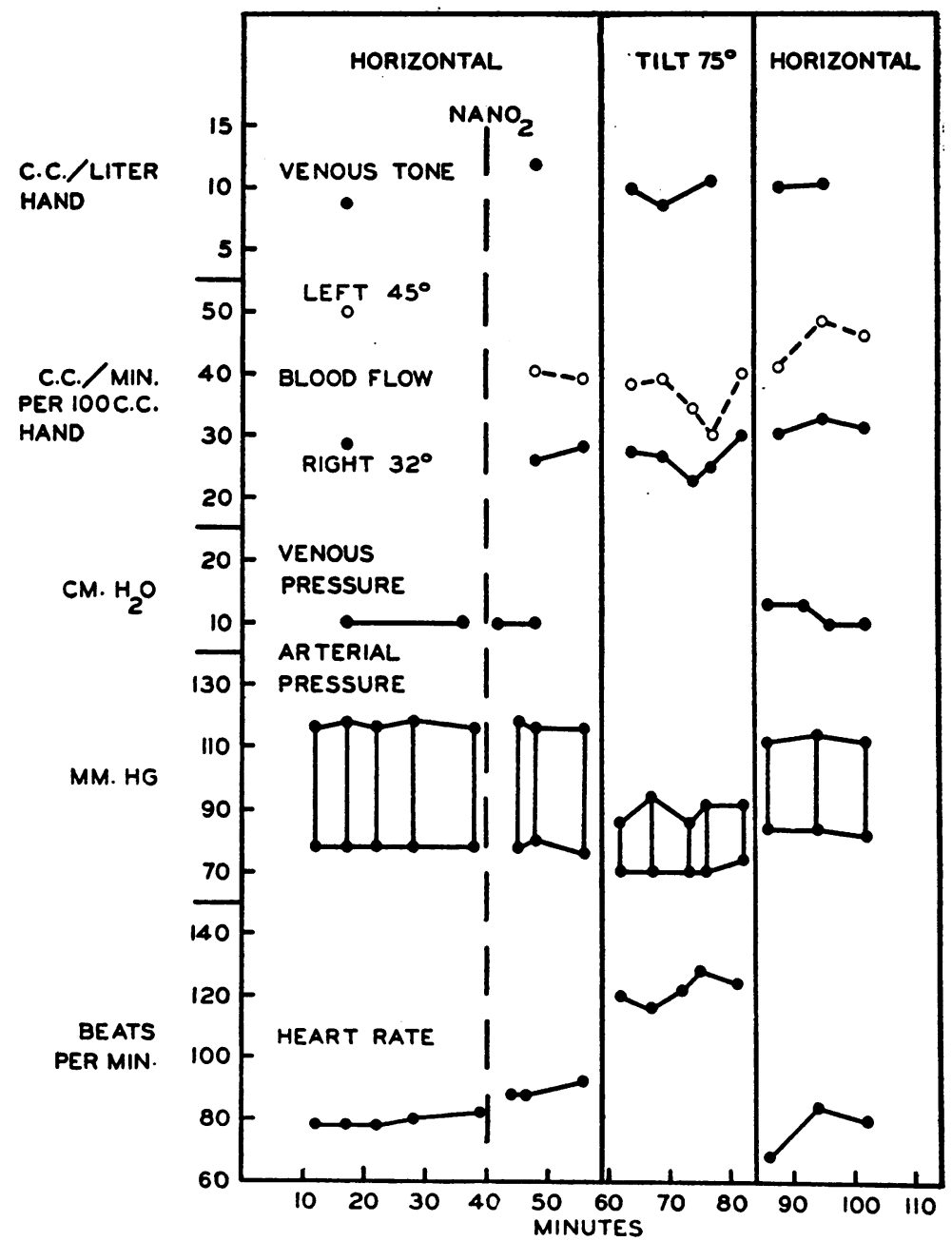

Fig. 5. Subject S. S. Effect of the Administration of 0.18 gram of Sodium Nitrite, Followed by Tilting to 75 Degrees

Curves as in Figure 1. 


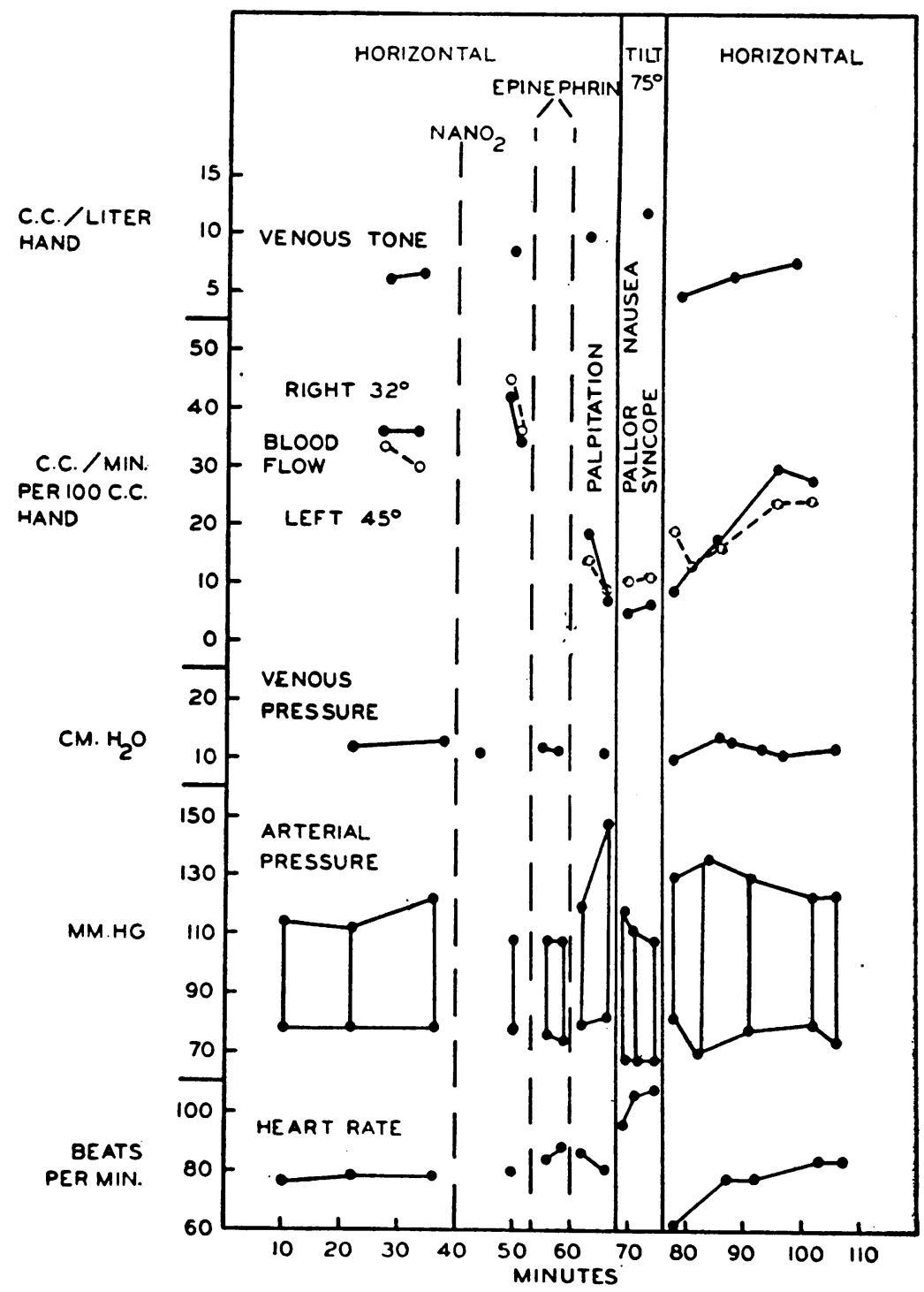

Fig. 6. Subject S. S. Effect of the Administration of 0.18 gram of Sodium Nitrite and 1.0 mgm. of Epinephrin, Followed by Tilting to 75 Degrees

Curves as in Figure 1.

It should be noted that these manifestations of collapse and syncope occurred with the arterial blood pressure maintained on a considerably higher level than after the administration of nitrite alone. The blood flow after nitrite and epinephrin, however, was severely curtailed. After nitrite alone, on the other hand, in spite of the fact that the arterial pressure was low, the flow through the tissues was adequate and no symptoms were present. As in other subjects, the increased cyanosis over the dependent part of the body observed after nitrite was not influenced by epinephrin. In this subject the venous tone in the hand was not increased after the combined effects of nitrite and epinephrin, but continued to decrease. In the horizontal position the venous tone usually became increased after epinephrin, even when this was administered after nitrite (Figures 7 and 8). That this constriction of the veins by epinephrin did not fully counterbalance 
the dilatation by nitrite in the major portion of the body is shown by the fact that collapse ensued when the subject was put in the upright position. The one constant effect of epinephrin was the sharp arteriolar constriction with marked restriction of blood flow.

\section{DISCUSSION}

The observations here presented are of both theoretical and practical interest. They throw light on: (a) the mechanism of collapse; $(b)$ the effect of epinephrin in an abnormal state of the circulation; (c) the rationale of treatment of vasomotor collapse.
Sodium nitrite induces no arteriolar constriction in the horizontal position. Its main effect consists in diminishing venous tone. The upright position, on the other hand, causes increased venous pressure over the dependent part of the body and arteriolar constriction (2). The combined vascular effects of sodium nitrite and of the upright position result then in acute tissue anoxia and finally in vasomotor collapse and syncope, mainly because of the simultaneous pooling of blood in the venules and veins and because of arteriolar constriction. Increased peripheral resistance and tissue anoxia also play a rôle in other types of syncope, collapse and shock $(9,10,11)$.

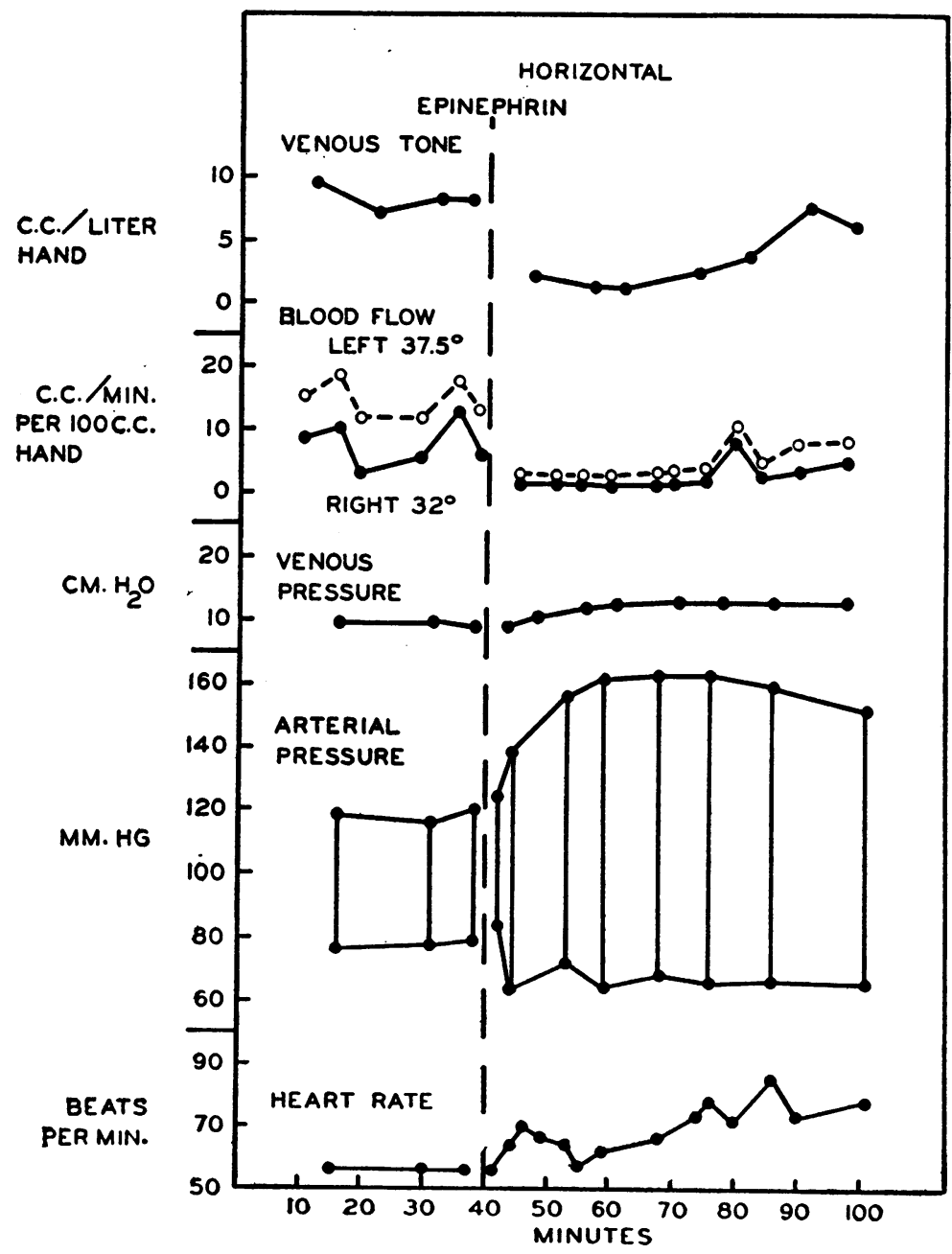

Fig. 7. Effect of the Administration of 1.0 MgM. OF Epinephrin to Subject C. P. in the Horizontal Position

Curves as in Figure 1. 


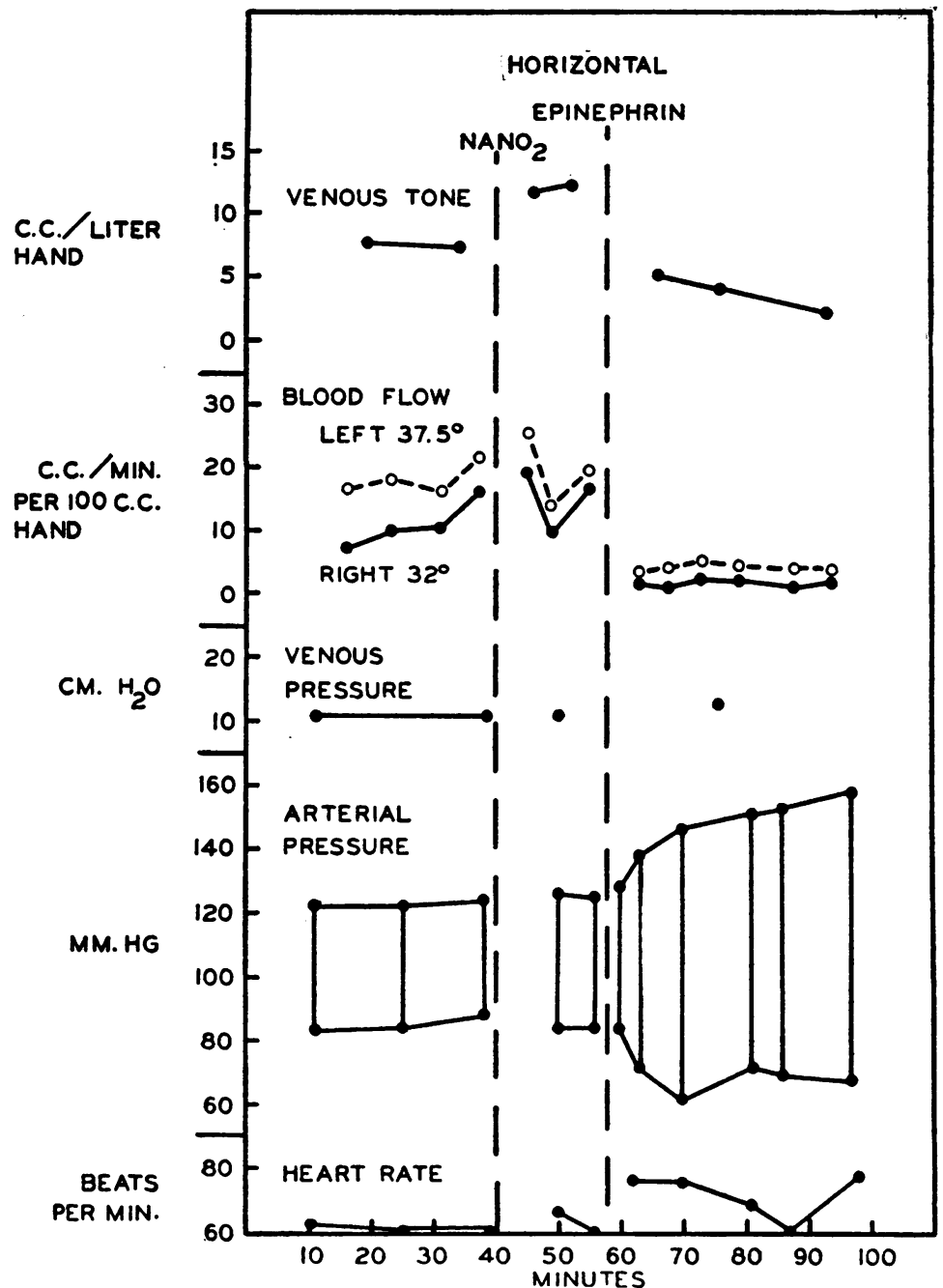

Fig. 8. Effect of the Administration of 0.18 gram of Sodium Nitrite and 1.0 mgm. of Epinephrin to Subject C. P. In the Horizontal Position

\section{Curves as in Figure 1.}

Epinephrin increases the arteriolar spasm produced by nitrite and tilting, as indicated by the behavior of the vessels and the blood flow of the hand as well as by the symptoms and signs. This arteriolar constriction, the combined effect of nitrite and epinephrin, is severe because the blood flow is considerably diminished even in the presence of relatively normal or elevated arterial pressure. It is known that epinephrin can produce marked constriction of the venous vessels (12). We have also observed that histamine in appropriate doses produces dilatation of the cutaneous venules only, without arteriolar dilatation (13). In this state, epinephrin, infused intra- venously in a ratio of about one (epinephrin hydrochloride) to three (histamine phosphate), usually just overcomes the venous dilatation without causing detectable arteriolar constriction, as indicated by the disappearance of cyanotic flush and unchanged skin temperature (14). Thus epinephrin can selectively constrict the cutaneous venules in man. From a theoretical consideration the balance between the arteriolar constrictor effect, which in collapse is harmful, and the venospastic effect, which is beneficial, determines the final rôle of epinephrin in nitrite collapse. In spite of the fact that epinephrin is capable of constricting the venules and veins, this action was 
found to be inadequate to overcome the decreased venous tone and pooling of blood in the presence of sodium nitrite collapse. In this condition, therefore, the arteriolospastic effect of epinephrin predominates and is not beneficial, but, as indicated by the experiments, is often harmful. It is possible that the final severe arteriolar spasm observed after the combined use of epinephrin and nitrite is the quantitatively synergistic result of a spasm produced by epinephrin and one previously existing as a result of sodium nitrite and the upright position. Although both the epinephrin effect and the nitrite collapse were associated with arteriolar spasm and tissue anoxia, the mechanism of the two states is essentially different, since epinephrin increases and nitrite decreases the venous tone. Hence the finding of arteriolar constriction or of a synergism between the effect of epinephrin and manifestations of collapse or shock does not justify the conclusion that the types of collapse or shock associated with increased arteriolar resistance are caused by epinephrin or epinephrin-like substances.

As the manifestations of collapse were observed in some of the experiments in the presence of relatively sustained arterial pressure, it is concluded that the arteriolar spasm observed in the hand must also have been present in other tissues, causing symptoms of anoxia of vital organs. The level of the arterial pressure, therefore, is not always a reliable index of the degree of collapse or tissue anoxia. Such a lack of parallelism between arterial pressure and various types of syncope $(15,16,17)$, collapse and shock (11) has been pointed out by us before. The experiments here presented demonstrate the underlying mechanism for this lack of correlation.

In the horizontal position, epinephrin produced arteriolar constriction and decreased flow through the hand, in spite of increased pulse pressure and elevated heart rate. Similarly, Fatherree and Brown (18) observed, both in normal subjects and in patients with arterial hypertension, constriction of the digital arterioles after the administration of epinephrin. This finding, together with the fact that moderate doses of epinephrin usually cause increased cardiac output $(19,14)$ and manifestations of overactivity of the circulation, indicates that in normal subjects in the hori- zontal position the digital arterioles are more sensitive to epinephrin than the "average systemic" arterioles, through which the flow must be increased.

The finding that epinephrin is not beneficial, but may be harmful in sodium nitrite collapse, does not justify the generalization that it is harmful in all types of collapse or shock. Previous observations have demonstrated that syncope, collapse or shock may be associated with various cardiovascular mechanisms and with either increased peripheral resistance (arteriolar constriction) or decreased peripheral resistance (arteriolar dilatation) $(11,15,16,17, \cdot 20)$. Furthermore, the state of the veins may be different. An arterioloconstrictor agent will be harmful in a type of syncope, collapse or shock which is associated predominantly with increased peripheral resistance, but it will be beneficial if the primary cause of the circulatory difficulty is decreased peripheral resistance. Thus, in collapse or shock caused by prolonged exposure to cold, heat is beneficial because it overcomes the vasospasm. In collapse or shock caused by excessive heat, on the other hand, application of cold, through vascular constriction, relieves the alarming manifestations of generalized peripheral vasodilatation. Even following a single stimulus, such as trauma, vasoconstriction may arise in one patient and dilatation in another, depending on factors which are not well understood (11). There are different types of syncope, collapse and shock, and knowledge of the mechanism of each of them is essential before rational treatment can be applied.

\section{SUMMARY AND CONCLUSIONS}

1. The effect of epinephrin has been studied in vasomotor collapse induced by sodium nitrite in subjects in the upright position.

2. Both in the horizontal and in the upright position, epinephrin in subcutaneous doses of 1.0 mgm. caused arteriolar constriction in and decreased blood flow through the hand. The venous tone became increased, as did the arterial pulse pressure and the heart rate; the venous pressure was usually slightly elevated.

3. Epinephrin did not prevent the vasomotor collapse and syncope produced by sodium nitrite, mainly because the arteriolar constriction and the 
tissue anoxia were enhanced and because the decreased venous tone produced by nitrite was not adequately compensated for.

4. The experiments indicate that the level of the arterial pressure is not a reliable index of the clinical manifestations of vasomotor collapse or of the degree of tissue anoxia.

5. The study presented throws light on the treatment of different types of vasomotor collapse. The fact that epinephrin is ineffective in nitrite collapse does not rule out its efficacy in other types of collapse.

This investigation was carried out with the technical assistance of Miss Sophia M. Simmons.

\section{BIBLIOGRAPHY}

1. Weiss, Soma, Wilkins, R. W., and Haynes, F. W., The nature of circulatory collapse induced by sodium nitrite. J. Clin. Invest., 1937, 16, 73.

2. Wilkins, R. W., Haynes, F. W., and Weiss, Soma, The rôle of the venous system in circulatory collapse induced by sodium nitrite. J. Clin. Invest., 1937, 16, 85.

3. Krogh, A., Turner, A. H., and Landis, E. M., A celluloid capsule for measuring venous pressures. J. Clin. Invest., 1932, 11, 357.

4. Smirk, F. H., Observations on the causes of oedema in congestive heart failure. Clin. Sc., 1936, 2, 317.

5. Moritz, F., and von Tabora, D., Uber eine Methode, beim Menschen den Druck in oberflächlichen Venen exakt zu bestimmen. Deutsches Arch. f. klin. Med., 1909-10, 98, 475.

6. Freeman, N. E., The effect of temperature on the rate of blood flow in the normal and in the sympathectomized hand. Am. J. Physiol., 1935, 113, 384.

7. Hewlett, A. W., and Van Zwaluwenburg, J. G., The rate of blood flow in the arm. Heart, 1909-10, 1, 87.
8. Capps, R. B., A method for measuring tone and reflex constriction of the capillaries, venules and veins of the human hand with the results in normal and diseased states. J. Clin. Invest., 1936, 15, 229.

9. Erlanger, J., Gesell, R., and Gasser, H. S., Studies in secondary traumatic shock. I. The circulation in shock after abdominal injuries. Am. J. Physiol., $1919,49,90$.

10. Freeman, N. E., Shaw, J. L., and Snyder, J. C., The peripheral blood flow in surgical shock. J. Clin. Invest., 1936, 15, 651.

11. Weiss, Soma, and Wilkins, R. W., Syncope, collapse and shock: their medical significance and their treatment. M. Clin. North America, 1937, 21, 481.

12. Fleisch, A., Venomotorenzentrum und Venenreflexe. I. Arch. f. d. ges. Physiol., 1930, 225, 26.

13. Weiss, Soma, Robb, G. P., and Ellis, L. B., The systemic effects of histamine in man with special reference to the responses of the cardiovascular system. Arch. Int. Med., 1932, 49, 360.

14. Weiss, Soma, Unpublished observations.

15. Weiss, Soma, and Baker, J. P., The carotid sinus reflex in health and disease. Its rôle in the causation of fainting and convulsions. Medicine, 1933, $12,297$.

16. Ferris, E. B., Jr., Capps, R. B., and Weiss, S., Carotid sinus syncope and its bearing on the mechanism of the unconscious state and convulsions. A study of 32 additional cases. Medicine, 1935, 14, 377.

17. Weiss, Soma, Syncope and related syndromes. Oxford Loose Leaf Med., 1935, 2, 250 (9). Oxford University Press, New York.

18. Fatherree, T. J., and Brown, G. E., The digital arterioles of normal and hypertensive individuals. Am. Heart J., 1937, 13, 1.

19. von Euler, U., and Liljestrand, G., Die Wirkung des Adrenalins auf das Minutenvolumen des Herzens beim Menschen. Skandinav. Arch. f. Physiol., 1927, 52, 243.

20. Weiss, Soma, and Wilkins, R. W., The nature of the cardiovascular disturbances in nutritional deficiency states (beriberi). Ann. Int. Med., 1937, 11, 104. 